\title{
Behavior Assessment of Children in Dental Settings: A Retrospective Study
}

\author{
${ }^{1}$ Arun Sharma, ${ }^{2}$ Rishi Tyagi \\ ${ }^{1}$ Professor, Department of Pedodontics and Preventive Dentistry, ITS Centre for Dental Studies and Research \\ Muradnagar, Ghaziabad, Uttar Pradesh, India \\ ${ }^{2}$ Reader, Department of Pedodontics and Preventive Dentistry, University College of Medical Sciences, New Delhi, India
}

Correspondence: Arun Sharma, Professor, Department of Pedodontics and Preventive Dentistry, E-48, First Floor, Lajpat Nagar-III New Delhi-110024, India, e-mail: drarunsharma05@yahoo.co.in

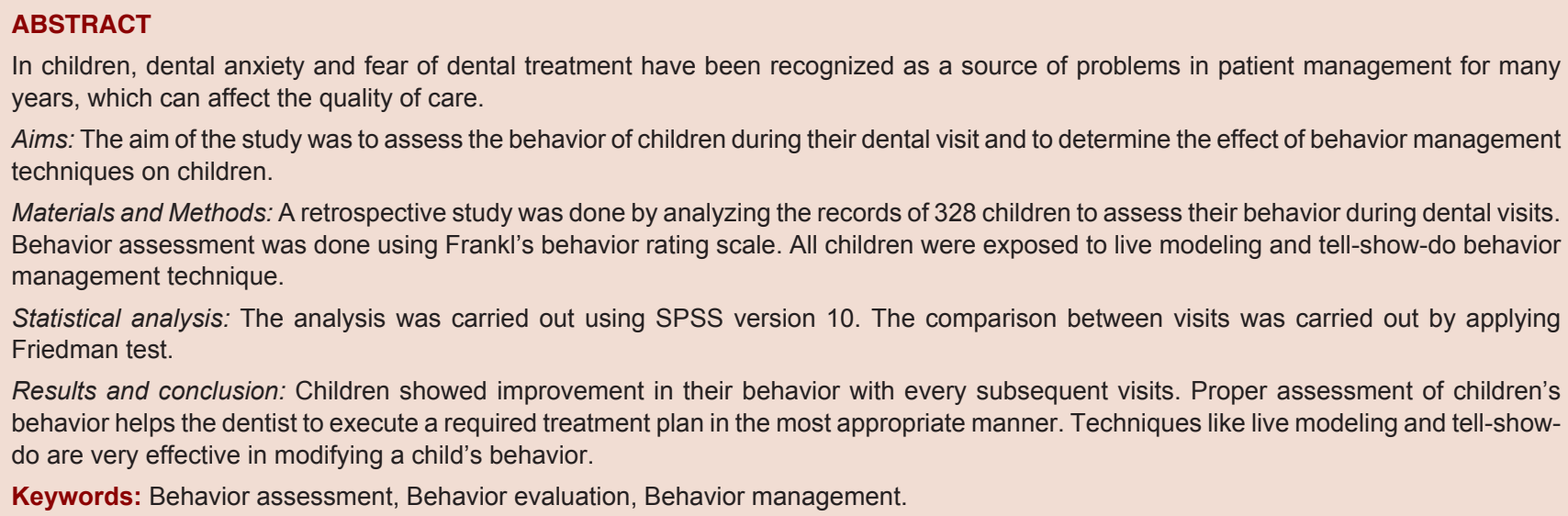

Statistical analysis: The analysis was carried out using SPSS version 10. The comparison between visits was carried out by applying Friedman test.

Results and conclusion: Children showed improvement in their behavior with every subsequent visits. Proper assessment of children's behavior helps the dentist to execute a required treatment plan in the most appropriate manner. Techniques like live modeling and tell-showdo are very effective in modifying a child's behavior.

Keywords: Behavior assessment, Behavior evaluation, Behavior management.

\section{INTRODUCTION}

Assessment of children based on their behavior is one of the most important skills for a pediatric dentist. ${ }^{1}$ The major aspect of child management in the dental care is managing dental anxiety and fear as it is considered to be the main barrier for successful completion of dental treatment. Children are known to have unfound fear and anxiety. The preschool children do not have the ability to understand a situation. They are in the very early stage of behavior development and little concern with the effect of their behavior on the observer. As the child enters the school, the child initiates the process of socializing and learning the conforming boundaries of behavior. Invariably, the pediatric dentists prefer to use pharmacological measures to achieve a required level of cooperation from very young children (preschool).

Many behavior rating scales are available to assess and evaluate the behavior of a child on each dental visit. Frankl et al classified child's behavior into four groups according to the child's attitude and cooperation or lack of cooperation during dental treatment. ${ }^{2}$ This classification is known as Frankl behavior rating scale, which is one of the most reliable tools developed for behavior rating of children in dental sittings.

The child's behavior on dental visit can be influenced by variables like age, parental behavior, parental anxiety, past medical and dental history, awareness of their dental problem, type of dental settings, behavior management and procedural techniques followed by the dentist. ${ }^{3}$

Several techniques for managing children in the dental office have been developed to modify a child's behavior. The nonpharmacologic tell-show-do technique which consists of verbal explanation of the procedure to the patient, demonstration for the patient of the (visual, auditory and tactile) aspects of the procedure and completion of the procedure, remains the most commonly used technique in pediatric dentistry. ${ }^{4,5}$

Modeling, nonpharmacologic behavior management technique was described by Bandura in 1967 as a process of acquiring behavior through observation of a model. Observing a peer (whether live/filmed) successfully undergoing dental treatment is effective in reducing children's fear and anxiety about the dental treatment..$^{6-8}$

The aim of the study was to analyze and assess the behavior of children during their dental visit and to 
determine the effect of behavior management techniques (tell-show-do and live modeling) on children.

\section{MATERIALS AND METHODS}

The study was conducted in the Department of Pedodontics and Preventive Dentistry, ITS Center for Dental Studies and Research, Ghaziabad, India, to assess the behavior of children during their dental visits and to determine the effect of behavior management techniques on children. The study was done by analyzing the records of 328 children between the age group of 2 to 14 years who had undergone dental treatment. The treatment rendered varied from oral prophylaxis to restorative pulp therapy and extractions.

\section{Selection Criteria}

The records of children undergone behavior assessment by operator for three dental visits to the department of pedodontics for dental treatment were included for the study.

Children were divided in four groups based on their ages. Group I (preschool) comprised of 17 children between age group of 2 and 3 years. Group II (kindergarden) comprised of 63 children between the ages of 4 and 5 years. Group III (primary school) comprised of 191 children between the age group of 6 and 10 years. Group IV (middle school) comprised of 57 children between the age group of 11 and 14 years.

During each visit (three visits), child had undergone assessment of behavior, i.e. pretreatment, during treatment and post-treatment. Behavior was recorded: (i) Before start of treatment (pretreatment) at the play therapy room, (ii) when treatment was rendered and (iii) post-treatment before relieving the patient from the department. Behavior assessment was done using Frankl's behavior rating scale. ${ }^{2,3}$

Definitely negative: Refusal of treatment, crying forcefully, fearful, or any other overt evidence of extreme negativizm.
Negative: Reluctant to accept treatment, uncooperative, some evidence of negative attitude but not pronounced (sullen, withdrawn).

Positive: Acceptance of treatment, at times cautious, willingness to comply with the dentist, at times with reservation, but patient follows the dentist's directions cooperatively.

Definitely positive: Good rapport with the dentist, interested in the dental procedures, laughing and enjoying.

Behavior was assessed by postgraduate students who were trained in behavior rating in the beginning of their curriculum. All children were exposed to an interaction with the operator in the play therapy room/reception area and then exposed to a positive live model in the dental clinic and then tell-show-do measure/technique was used on the dental chair.

The analysis was carried out using SPSS version 10 . For statistics analysis, numerical value was assigned to Frankl's behavior rating scale (Definitely negative- 0 , negative -1 , positive -2 , definitely positive -3 ). The comparison between visits was carried out by applying Friedman test and $\mathrm{p}$-value $<0.05$ was taken as significant.

\section{RESULTS}

The results are summarized in Tables 1 to 4 .

\section{DISCUSSION}

In our study in group I, six (35.29\%) of the children were definitely negative on Frankl's behavior rating scale and by the end of the 1st visit four more children had shown decreased level of cooperation and were graded as definitely negative. By the 2nd visit two (11.76\%) children were graded as definitely negative, which is indicative of a better response in the 2nd visit of the same children. During treatment, two $(11.76 \%)$ children showed a definitely negative behavior in the 3rd visit, this indicates lack of comprehension and understanding achieved by child.

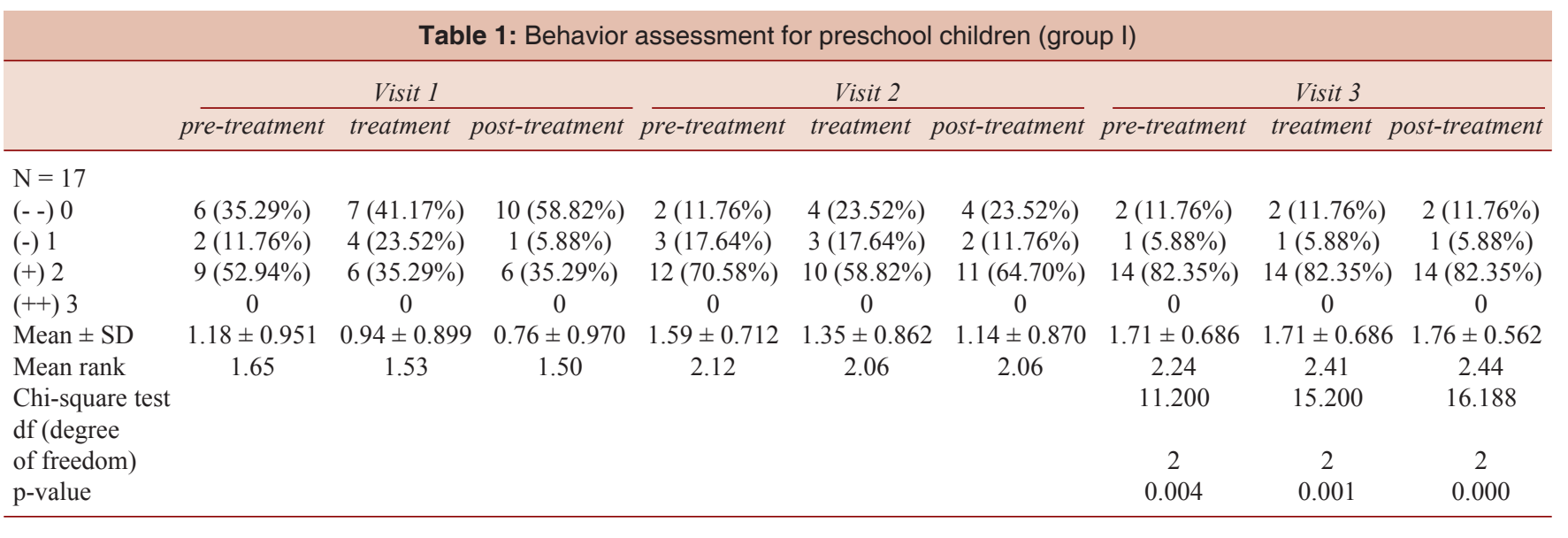


Table 2: Behavior assessment for kindergarden children (group II)

Visit

Visit 2

Visit 3

$\overline{\text { pre-treatment treatment post-treatment }} \overline{\text { pre-treatment treatment post-treatment }} \overline{\text { pre-treatment treatment post-treatment }}$

$\mathrm{N}=63$

$(--) 0$

$(-) 1$

(+) 2

$(++) 3$

$\begin{array}{ccc}3(4.76 \%) & 4(6.34 \%) & 8(12.69 \%) \\ 13(20.63 \%) & 21(33.33 \%) & 17(26.98 \%)\end{array}$

$\begin{array}{lll}0 & 1(1.58 \%) & 2(3.17 \%)\end{array}$

0

$0 \quad 1(1.58 \%)$

Mean \pm

$\begin{array}{lllllllll}47(74.60 \%) & 38(60.31 \%) & 38(60.31 \%) & 47(74.60 \%) & 37(58.73 \%) & 38(60.31 \%) & 47(74.60 \%) & 45(71.42 \%) & 39(61.90 \%)\end{array}$

0

$1.67 \pm 0.568 \quad 1.54 \pm 0.618 \quad 1.48 \pm 0.715$

$\begin{array}{llllll}5(7.93 \%) & 8(12.69 \%) & 5(7.93 \%) & 9(14.28 \%) & 9(14.28 \%) & 16(25.39 \%)\end{array}$

Mean rank

Chi-square test

1.70

1.63

1.55

2.06

2.06

1.93

$2.03 \pm 0.507 \quad 2.00 \pm 0.539 \quad 2.13 \pm 0.660$

df (degree of

freedom)

p-value

(n)

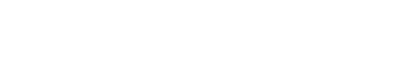

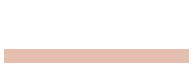

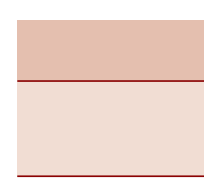

Table 3: Behavior assessment for primary school children (group III)

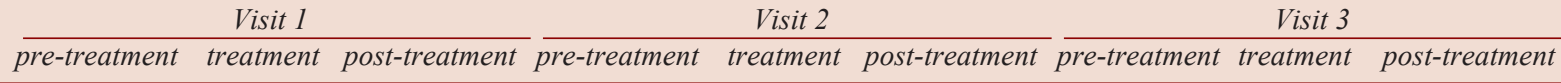

$\mathrm{N}=191$

$(--) 0$

$(-) 1$

(+) 2

$(++) 3$

Mean \pm SD

Mean rank

Chi-square test

df (degree of

freedom)

p-value

\begin{tabular}{|c|c|c|c|c|c|c|c|c|}
\hline $2(1.04 \%)$ & $2(1.04 \%)$ & $4(2.09 \%)$ & $1(0.52 \%)$ & $1(0.52 \%)$ & $1(0.52 \%)$ & 0 & $1(0.52 \%)$ & $1(0.52 \%)$ \\
\hline $6(3.14 \%)$ & $29(15.18 \%)$ & $35(18.32 \%)$ & $5(2.61 \%)$ & $11(5.75 \%)$ & $26(13.61 \%)$ & $2(1.04 \%)$ & $8(4.18 \%)$ & $14(7.32 \%)$ \\
\hline $183(95.81 \%)$ & $160(83.76 \%)$ & $152(79.58 \%)$ & $183(95.81 \%)$ & $173(90.57 \%)$ & $155(81.15 \%)$ & $183(95.81 \%)$ & $175(91.62 \%)$ & $158(82.72 \%)$ \\
\hline 0 & 0 & 0 & $2(1.04 \%)$ & $6(3.14 \%)$ & $9(4.71 \%)$ & $6(3.14 \%)$ & $7(3.66 \%)$ & $18(9.42 \%)$ \\
\hline $1.95 \pm 0.266$ & $1.83 \pm 0.406$ & $1.77 \pm 0.466$ & $1.97 \pm 0.239$ & $1.96 \pm 0.330$ & $1.91 \pm 0.456$ & $2.02 \pm 0.204$ & $1.98 \pm 0.316$ & $2.02 \pm 0.441$ \\
\hline \multirow[t]{4}{*}{1.95} & 1.85 & 1.81 & 1.99 & 2.06 & 2.02 & 2.06 & 2.09 & 2.17 \\
\hline & & & & & & 21.571 & 53.067 & 69.391 \\
\hline & & & & & & 2 & 2 & 2 \\
\hline & & & & & & 0.000 & 0.000 & 0.000 \\
\hline
\end{tabular}

Table 4: Behavior assessment for middle school children (group IV)

$\begin{array}{llll}\text { Visit } 1 & \text { Visit } 2 & \text { Visit } 3\end{array}$

$\overline{\text { pre-treatment treatment post-treatment }} \overline{\text { pre-treatment }}$ treatment post-treatment $\overline{\text { pre-treatment treatment post-treatment }}$

$\mathrm{N}=57$

$(--) 0$

$(-) 1$

(+) 2

$(++) 3$

Mean \pm SD

Mean rank

Chi-square test

df (degree

of freedom)

p-value

\begin{tabular}{|c|c|c|c|c|c|c|c|c|}
\hline 0 & 0 & 0 & 0 & 0 & 0 & 0 & 0 & 0 \\
\hline $3(5.26 \%)$ & $6(10.52 \%)$ & $7(12.28 \%)$ & 0 & $2(3.50 \%)$ & $3(5.26 \%)$ & 0 & 0 & 0 \\
\hline $43(75.43 \%)$ & $44(77.19 \%)$ & $46(80.70 \%)$ & $51(89.47 \%)$ & $50(87.71 \%)$ & $50(87.71 \%)$ & $48(84.21 \%)$ & $46(80.70 \%)$ & $46(80.70 \%)$ \\
\hline $11(19.29 \%)$ & $7(12.28 \%)$ & $4(7.01 \%)$ & $6(10.52 \%)$ & $5(8.77 \%)$ & $4(7.01 \%)$ & $9(15.78 \%)$ & $11(19.29 \%)$ & $11(19.29 \%)$ \\
\hline $2.14 \pm 0.480$ & $2.02 \pm 0.481$ & $1.95 \pm 0.440$ & $2.11 \pm 0.310$ & $2.05 \pm 0.350$ & $2.02 \pm 0.353$ & $2.16 \pm 0.368$ & $2.19 \pm 0.398$ & $2.19 \pm 0.398$ \\
\hline \multirow[t]{3}{*}{2.01} & 1.89 & 1.84 & 1.96 & 1.95 & 1.95 & 2.04 & 2.16 & 2.21 \\
\hline & & & & & & 1.750 & 14.000 & 22.286 \\
\hline & & & & & & 0.417 & 0.001 & 0.000 \\
\hline
\end{tabular}

Number of children showing positive response had reasonably increased by the end of 3rd visit. A very small number of children did not cooperate for routine dental treatment. Simple counseling, tell-show-do and live modeling did have a great impact on younger children (preschool). This is especially important in our setup, as parents are increasingly apprehensive and less willing to allow the use of conscious sedation or undertake general anesthesia. In the age group of 4 to 5 years (group II) the number of children in definitely negative category were three (4.76\%) and $13(20.63 \%)$ were graded as negative. At the end of initial counseling and live modeling, five children become more uncooperative (definitely negative) and 17 children showed lack of the cooperation (negative). By the end of 3rd visit only one (1.58\%) child was definitely negative and seven $(11.11 \%)$ children were negative. In fact, for 4 to 5 years children these psychological measures are impressively effective and can create extremely good patient at this stage of life, as $16(25.39 \%)$ were definitely positive by the end of the 3 rd visit.

In our study, children showed improvement in their behavior on subsequent visits. Frankl studied the cooperative behavior of 3 to 5 years old children during dental visit and concluded that cooperative behavior 
increases on second visit. $^{2}$ Howitt and Stricker also concluded in their study that child's arousal level was reduced as he gained experience in the dental situation. ${ }^{9}$ Venham and Cipes have also shown that the behavior of children improves in subsequent dental visits. ${ }^{10}$ The improvement during subsequent visits suggests that the experience gained by the child during previous visits helped the child to recognize the nonthreatening aspects of the visits and to deal with stressful dental procedures.

In group III between the age group of 6 to 10 years, the children are grown up and expected to understand and cooperate during dental treatment. However, we had four $(2.09 \%)$ children showing definitely negative behavior during the end of 1 st visit, and by the end of $3 \mathrm{rd}$ visit one $(0.52 \%)$ child showed definitely negative behavior, although we have not assessed their family background and reason for the uncooperative behavior. It is possible to create positive attitude in this age group and achieve all possible treatment without the use of conscious sedation or general anesthesia. The gross reason for uncooperative behavior could be due to pain at the time of treatment. Corkey and Freeman have reported that dental anxiety begins to decrease by 6 to 7 years, with most children being able to cope with dental situations at that age. ${ }^{11}$ Holst and Crossner, ${ }^{12}$ and Klingberg et $\mathrm{al}^{13}$ have also established that dental anxiety was more pronounced in younger children (4-6 years) as compared to older children (9-11 years). Differences in child's reaction to dental treatment according to age have been well-established. ${ }^{14,15}$

Age group beyond 10 years (group IV) shows a uniform positive behavior and willingness to cooperate and undergo necessary treatment. All negative images and thoughts are erased by the 3 rd dental visit.

It is extremely important that child must be given due consideration on there visit to dental department, and simple behavior management techniques can have profound effect in achieving our goals to impart good oral health and the positive attitude towards dentistry. Pediatric dentist frequently face behavior management problems and continue to seek safe, cost-effective techniques for managing difficult children. Parental acceptance of behavior management technique used by pediatric dentist is another concern. Parents reported a significant preference for noninvasive reinforcement techniques instead of sedation and restrains. ${ }^{16}$ General principles were established to gauge the validity of behavior management techniques at the conference of the American Academy of Pediatric Dentistry in 2003: (a) Effectiveness - the potential of the technique to manage children's behavior in the dentist's office, (b) Social validity - acceptance of the technique by parents as well as public perception of the technique, (c) Risk associated with the technique, (d) Cost - time spend practicing the technique and cost of any materials and equipment used. ${ }^{17}$

Modeling (model learning) has been suggested as a method for introducing the child to dentistry. ${ }^{6,18}$ In this approach, the ability of the child to imitate others is used and by imitating, the child learns complex behavior patterns. Two forms of modeling, live and filmed, are effective in reducing children's fear and anxiety about dental treatments and promoting adaptive behavior. ${ }^{8,19}$ Tell-show-do method is still considered the technique with which dentists and parents are most comfortable. ${ }^{17,20}$

In our study, these two behavior management techniques were effective in reducing child's fear and anxiety as most of the children in our study were showing cooperative behavior by the end of 2 nd or 3 rd visit. The methods of behavior management should be designed, so that the child willingly returns to the clinic for regular check-ups through out the childhood years and into adult life with no reluctance. The use of pharmacological agents in the management of fearful or anxious child may help to achieve the treatment plan, but these approaches should never be seen as an alternative to manage the uncooperative child patient because of time constraint on the part of the dentist and should only be employed when absolutely indicated.

\section{CONCLUSION}

Assessment of behavior is the most important tool in the hands of the dentist. This helps the dentist to execute required treatment plan in the most appropriate manner in children. Simple techniques like preparation of the child in nondental settings, like a play therapy room or a play area can be instrumental in instilling a positive behavior in a child. Techniques like live modeling and tell-show-do are very effective in achieving treatment goals in all age groups.

\section{REFERENCES}

1. Shinohara S, Nomura Y, et al. Structural relationship of child behavior and its evaluation during dental treatment. J Oral Science 2005;47(2):91-96.

2. Frankl SN, Shiere FR, Fogels HR. Should the parent remain with the child in the dental operatory? J Dent Child 1962;29: 150-63.

3. McDonald RE, Avery DR, Dean AJ. In: Dentistry for the child and adolescent (8th ed). St. Louis: Mosby 2004.

4. Allen KD, Stanley RT, McPherson K. Evaluation of behavior management technology dissemination in pediatric dentistry. Pediatr Dent 1990;12(2):79-82.

5. Adair SM, Waller JL, Schafer TE, Rockman R. A survey of members of the American Academy of Pediatric Dentistry on their use of behavior management techniques. Pediatr Dent 2004;26(2):159-66.

6. Adelson D, Goldfried M. Modeling and fearful child patient. J Dent Child 1970;37:476-88. 
7. Melamed BG, Hawes R, Heiby E, Glick J. The use of film modeling to reduce uncooperative behavior of children during dental treatment. J Dent Res 1975;54:797-801.

8. Greenbaum PE, Melamed BG. Pretreatment modeling. A technique for reducing children fear in the dental operatory. Dent Clin North Am 1988;32(4):693-704.

9. Howitt JW, Stricker G. Sequential changes in response to dental procedures. J Dent Res 1970;49:1074-77.

10. Venham L, Bengston D, Cipes M. Children's response to sequential dental visits. J Dent Res 1977;56:454-59.

11. Corkey B, Freeman R. Predictors of dental anxiety in six year old children: Findings of a pilot study. J Dent Child 1988;55: 231-36.

12. Holst A, Crossner CG. Direct rating of acceptance of dental treatment in Swedish children. Community Dent Oral Epidermiol 1987; 15:258-63.

13. Klinberg G, Berggren U, Carlson SG, Noren JG. Child dental fear: Cause related factors and clinical effects. Eur J Oral Science 1995;103:405-12.
14. Klein H. Psychological effects of dental treatment on children of different ages. J Dent Child 1964;31:146-50.

15. Wright GZ, Alpern GD. Variables influencing children's cooperative behavior at the first dental visit. J Dent Child 1971; 38:60-64.

16. Murphy MG, Fields HW, Machen JB. Parental acceptance of pediatric dentistry behavior management techniques. Pediatr Dent 1984;6:193-98.

17. Adair SM. Behavior management conference panel I reportrational for behavior management techniques in pediatric dentistry. Pediatr Dent 2004;26(2):167-70.

18. Chambers DW. Managing the anxieties of young dental patients. J Dent Child 1970;37:363-74.

19. Rouleau J, Ladouceur R, Dufour L. Pre-exposure to the first dental treatment. J Dent Res 1981;60(1):30-34.

20. Eaton JJ, McTigue DJ, Fields HW (Jr), Beck M. Attitudes of contemporary parents towards behavior management techniques used in pediatric dentistry. Pediatr Dent 2005;27(2):107-13. 